\title{
OTRA VUELTA A LA IDENTIDAD LATINOAMERICANA EN LOS ESTUDIOS LITERARIOS Y CULTURALES
}

\author{
ANOTHER TURN ON LATIN AMERICAN IDENTITY \\ IN CULTURAL AND LITERARY STUDIES
}

\section{OLGA OSTRIA REINOSO${ }^{1}$}

\section{RESUMEN}

El presente trabajo surge de la continua necesidad teórica de repensar las categorías que buscan interpretar los fenómenos socioculturales a través de las obras literarias, específicamente la de identidad cultural latinoamericana. Para ello se lleva a cabo una labor de historización del término: recorrido por los usos y transformaciones semánticas que la noción ha sufrido; en un esfuerzo por respetar la especificidad de los ámbitos de reflexión que se ven convocados mediante este tipo de estudios, como también -y especialmente- de recuperar las posibilidades crítico-analíticas del concepto. En este tenor, el artículo procura ofrecer un contexto teórico-metodológico a las investigaciones literario-culturales que día a día actualizan la noción de identidad y los debates en torno a ella.

Palabras clave: Identidad cultural latinoamericana, categorías analíticas, crítica literaria, estudios culturales, alteridad.

\section{ABSTRACT}

This paper is a response to the ever present theoretical necessity to rethink the categories that seek to interpret sociocultural phenomena through literary works, specifically the category of Latin American cultural identity. In order to accomplish this, an historization of the term is carried out consisting of a tour through the semantic uses and transformations that it has passed through over time in an effort to respect the

${ }^{1}$ El presente artículo es resultado del proyecto de investigación "Discursos identitarios en las crónicas urbanas de Monsiváis, Lemebel y Alcalde”, código 103126 1/I, Universidad del Bío-Bío.

${ }^{2}$ Doctora en Estudios Latinoamericanos (UNAM). Profesora del Departamento de Estudios Generales Universidad del Bío-Bío. Concepción, Chile. E-mail: eostria@ubiobio.cl 
specificity of the environments of reflection that are called up by this type of study, as well as -and especially-for recovering the critical analytical possibilities of the concept. In this spirit, the paper offers a theoretical-methodological context to literary-cultural research that day by day updates the notion of identity and the debates around it.

Keywords: Latin American cultural identity, analytical categories, literary criticism, Cultural Studies, otherness.

Recibido: 09.03.11. Aceptado: 05.01.11.

$\mathrm{E}$ L PRESENTE TRABAJO surge de una continua necesidad analítica, teórica, de repensar las categorías que buscan interpretar los fenómenos socioculturales a través de las obras literarias. Ideología, memoria, cultura, cultura popular, por nombrar algunas, constituyen categorías “anfibias" que parecen resistir prácticamente toda utilización metodológica que pretenda tender puentes interdisciplinarios. Una de las más problemáticas es la de identidad y, específicamente, la de identidad latinoamericana, en la medida en que ha sido empleada casi indiscriminadamente en innumerables estudios para también gran número de fines y disciplinas que han terminado, en muchas ocasiones, por vaciarla de sentido, de capacidad explicativa y, desde luego, de potencial crítico. Se trata, sin embargo, de una noción cuya virtual utilidad se ve regenerada en esta última década, no sólo porque, en efecto, permite vincular distintas esferas del conocimiento, sino porque contribuye al análisis de muchos fenómenos culturales actuales relacionados, por ejemplo, con la globalización, las nuevas formas de exilio, las dinámicas urbanas, los flujos transnacionales, la desterritorialización cultural, etc. Las discusiones alrededor de estos temas y sus conexiones con lo identitario se reabren constantemente, por lo que, al parecer, no es un mal momento para volver a detenerse seriamente en las identidades culturales de América Latina.

Una de las tareas cardinales a la hora de reexaminar las mencionadas nociones consiste en someterlas a un proceso de historización, es decir, explicar el proceso de transformaciones semánticas y de uso que el concepto ha experimentado (en América Latina y fuera de ella), en un esfuerzo por respetar la especificidad de los ámbitos de reflexión que se ven convocados mediante este tipo de estudios, por un lado, y por recuperar las posibilidades crítico-analíticas del concepto, por otro. En este tenor, nuestro artículo procura ofrecer un contexto teórico-metodológico a las investigaciones literario-culturales que día a día actualizan la noción de identidad y los debates en torno a ella. 


\section{SOBRE LA IDENTIDAD LATINOAMERICANA}

Si bien el término 'identidad' es de uso relativamente reciente, la voluntad por definir lo latinoamericano nos acompaña de forma persistente desde, al menos, el inicio de los movimientos de emancipación e independencia en nuestras tierras ${ }^{3}$. Este afán casi obsesivo por determinar nuestras 'peculiaridades', 'especificidades' o aquellos rasgos 'auténticos' a partir de los cuales distinguirnos de los colonizadores, responde, como ya bien sabemos, a una búsqueda de reconocimiento y de autonomía cultural respecto de las metrópolis europeas. En ese sentido es que tal objetivo constituye, a grandes rasgos, un gesto de liberación, de independencia y, en último término, una señal defensiva. Así, la problemática se asocia en la práctica -y en palabras de Raúl Dorra (1986) - a una "inspiración ideológica" (49), dado su esencial vínculo a una estrategia de poder y a un proyecto histórico: el de la integración de los países de la región con fines libertarios. "La idea de 'unidad latinoamericana' -señala con acierto Rosalba Campra (1998)- aparece pues ligada indisolublemente a la lucha contra la condición de colonizado, contra la definición impuesta desde afuera por las presiones económicas, políticas, culturales: unidad no tanto de lengua o de origen, sino más bien de problemáticas" (18).

Las profundas secuelas de la condición colonial y la eterna dependencia de nuestros países explican en parte la continua inquietud por el tema de la identidad y patentizan, asimismo, su carácter de proceso inacabado. De modo que el propio cuestionamiento, el hecho de formularnos una y otra vez la pregunta por nuestra identidad, es a un tiempo signo de esa identidad que se persigue. Por eso es que, entre otros factores, ella no puede entenderse como una esencia, como algo fijo que debe desentrañarse, sino como un devenir y como una búsqueda continuamente redefinida, resemantizada y recomenzada.

Llegado el siglo XIX, el surgimiento de las ideas "nacionales" viene a reforzar la atención en el problema de la identidad. En efecto, la constitución de la nación -fundada en una necesaria construcción identitaria- es, como lo ha expresado Renato Ortiz ${ }^{4}$, requisito fundamental de desarrollo; nación (e identidad nacional) y progreso se vuelven, en este contexto, sinónimos.

\footnotetext{
${ }^{3}$ Más ampliamente aún, el intento por precisar “lo americano” está presente en la historia del continente, desde su descubrimiento hasta nuestros días, como ha señalado, entre otros, Fernando Aínsa (1986).

${ }^{4}$ Véase, por ejemplo, Ortiz (2000 y 1996).
} 


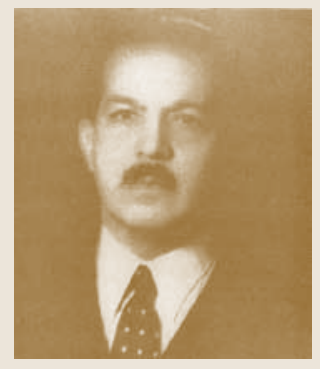

P. Henríquez Ureña
De este planteamiento que enlaza las nociones de identidad y nación, abstraemos dos implicancias en las cuales es preciso detenerse:

1. la impronta romántica que carga la preocupación por la identidad de la región.

2. el impacto que la crisis acerca de la idea de nación tiene sobre la noción de identidad.

1. A lo largo de todo el siglo XIX y la mayor parte del XX el recorrido en busca de "lo latinoamericano", en cuanto esfuerzo por especificar una naturaleza, una esencia que nos hiciera únicos, diferentes y reconocidos universalmente, y que, al mismo tiempo, nos condujera al progreso, se presenta como la búsqueda de un centro que sea capaz de asimilar y sintetizar toda la diversidad cultural y racial de cada país y, a su vez, de la región. Este principio de homogeneización e integración en el cual se inspiran los proyectos nacionales y continentales se verá reflejado en la creación de categorías de pensamiento como las de "mestizaje", "sincretismo", "autenticidad", o incluso y más tarde, en imágenes colmadas de misticismo como las de "raza cósmica" y "energía nativa", por nombrar las más recurrentes. Todas ellas ilustran la tendencia romántica que empapa y da forma a estos proyectos de unificación, en la medida en que procuran fusionar pasado y presente, apropiarse de los orígenes para construir un futuro. Ya lo dijo en su momento Pedro Henríquez Ureña (1972): "El problema de la expresión genuina de cada pueblo está en la esencia de la rebelión romántica" (217). Desde este horizonte, no está de más recordar que es el movimiento romántico (en especial el romanticismo alemán de Herder) el que se especializa en buscar el genio nacional, el alma de la lengua, la fuente de las tradiciones, el origen de los orígenes.

Las ideas afanadas en definir un "ser nacional" y un "ser latinoamericano" tendrán, desde luego, expresión en la literatura y en la artes de América Latina a través de muy variadas formas, entre las que destaca la presencia del anhelo nostálgico de reunión con la naturaleza, con el cosmos, con el ser humano y, al mismo tiempo, la decepcionante constatación de las profundas fronteras que impiden tal reconciliación. Esa "urgencia romántica de expresión” (217) de la que padecemos, según el mismo Henríquez Ureña, se manifiesta en nuestras letras hasta bien entrado el siglo XX, y sus huellas pueden encontrarse sin mayor dificultad en numerosas obras literarias contemporáneas.

De manera que las ansias de integración nacional y regional que caracterizan los planteamientos políticos y culturales de este periodo, encuen- 
tran correspondencia en aquellos anhelos románticos expresados por las artes de rebasar la parte para encontrar el todo. En definitiva, el pensamiento romántico deviene eje fundamental que configura tanto las reflexiones sobre una identidad latinoamericana como las diversas manifestaciones a través de las cuales ella se revela.

2. Las últimas décadas del siglo recién pasado traen consigo una serie incontable de cuestionamientos en múltiples instancias de reflexión, los cuales tienen que ver, en muchos casos, con el desencanto y la duda respecto de determinados supuestos atribuidos a la Modernidad, y que, por tanto, se inscriben dentro de las corrientes de pensamientos que se han dado en llamar posmodernas, contexto en el cual podemos inscribir también a los Estudios Culturales 5 . Una de aquellas controversias se dirige implacable hacia la idea de nación o de Estado-nación. Si bien se trata de un conjunto de objeciones (de orden político, económico, social y cultural), nos enfocaremos aquí en la crítica orientada hacia la supuesta unidad de esta entidad, hacia la concepción de ésta como una totalidad cultural homogénea. Según esta perspectiva, las profundas diferencias culturales entre los habitantes de una misma nación han sido enmascaradas en pos de un organismo supuestamente artificial. La concepción esencialista o sustancialista de identidad, por consiguiente, se ve de igual forma profundamente erosionada por las nuevas miradas. Se la considera una noción estática que tiende a homogeneizar los grupos culturales y, en consecuencia, a ignorar las heterogeneidades regionales, sociales, étnicas, etc. Por lo que se tratará, entonces, de asumir una visión dinámica y plural, constitutiva de discursos identitarios que se van construyendo como imaginarios culturales. En este orden reflexivo, se privilegia la idea de 'diversidad cultural' o 'multiculturalidad', con la cual se reconoce una proliferación infinita de "identidades culturales" (minorías étnicas, sexuales y hasta generacionales), como las ha clasificado Stuart Hall (1991). De modo tal que aquella advertida equivalencia entre los conceptos de "identidad" y "nación" parece ahora desvanecerse. El asunto se complica y acentúa al situar todo este panorama en el contexto de la renombrada globalización: nuevas identidades surgen ahora a partir de los flujos de información transnacionales ${ }^{6}$, como aquellas que Habermas (1998) ha calificado de "formas posnacionales de identidad" o aquellas "identidades desterritorializadas" a las que hacen referencia García Canclini (1990) o Martín Barbero (1987), entre otros.

\footnotetext{
${ }^{5}$ Véase Viñas Piquer (2002).

${ }^{6}$ Véase Martín Barbero (2000).
}

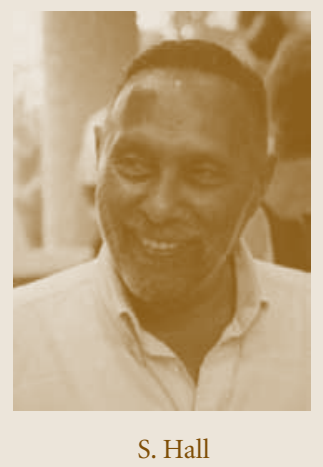

S. Hall 
En dicho entorno, pensar en una identidad regional latinoamericana, evidentemente obliga, ha obligado, a asumir nuevos enfoques.

Durante los últimos años, la noción de 'hibridación' ha dominado, en muchos aspectos, los acercamientos a la problemática de las identidades; término que, según el mismo García Canclini -quien lo hace suyo-, permite dar cuenta de la variedad y complejidad de los procesos de mezcla e interacción culturales que se llevan a cabo en Latinoamérica en el globalizado escenario actual.

Sin embargo, a partir de estos renovados puntos de vista surgen nuevas interrogantes y se advierten otras carencias o deficiencias críticas, entre los cuales habrá que considerar muy especialmente:

1. La falta de una actitud crítica fundamental en los Estudios Culturales, subyacente, por ejemplo, en el empleo de términos como 'multiculturalismo' e 'hibridación', implicados en la temática de las identidades. Aun cuando el acento puesto en la diversidad cultural por los Estudios Culturales (norteamericanos y latinoamericanos) colaboró en la tarea de desenmascarar el proyecto homogeneizador representado por el concepto de nación, revistió el problema con una nueva máscara. Efectivamente, esta especie de exaltación de la pluralidad cultural tiende a ocultar o a restar atención a las profundas diferencias sociales existentes en América Latina ${ }^{7}$. Lo diverso encubre lo desigual, lo neutraliza en una sinonimia mentirosa. Desigualdades sociales, contradicciones clásicas cada vez más antagónicas no desaparecen, pero son celebradas como expresión genuina del espíritu democrático. Algo similar ocurre con la concepción de 'hibridación' que, desde esta óptica, resulta una actualización de la de mestizaje, puesto que apunta, en última instancia, a una síntesis relativamente armoniosa y conciliatoria conformada en el espacio de la hegemonía; dicha categoría, en consecuencia, tampoco permite dar cuenta a cabalidad de la coexistencia altamente conflictiva presente en los pasados y actuales procesos culturales latinoamericanos. Se trata, finalmente, de una hibridación y un multiculturalismo inocuos; tranquilizadores, pero engañosos.

Desde una mirada que pretende vincular cultura ${ }^{8}$ y sociedad $y$, en ese

\footnotetext{
${ }^{7} \mathrm{Al}$ respecto, Jean Baudrillard ha sentenciado en La transparencia del mal: "[...] mientras la diferencia prolifera al infinito, en la moda, en las costumbres, en la cultura, la alteridad dura, la de la raza, la locura, la miseria se ha convertido en un producto escaso". Citado por Martín Barbero (2000: 19).

${ }^{8}$ Concebimos aquí la noción de cultura, según lo expresado por Francoise Perus (1995), como "un conjunto más o menos heterogéneo de elementos materiales y espirituales histórica-
} 
tenor, subrayar las contradicciones y el conflicto (ni superados ni sintetizados) inherentes a nuestros procesos culturales, nos parece que, por ejemplo, las categorías de "totalidad contradictoria" y "heterogeneidad no dialéctica"9 desarrolladas por Antonio Cornejo Polar desde el ámbito de la historiografía y crítica literarias, contribuyen notablemente a un enfoque de tal naturaleza.

2. La necesidad de nuevas formas de vinculación social que sean capaces de contrarrestar la fragmentación resultante de la perpetua multiplicación de identidades. El ensalzamiento acrítico de la diferencia -"la esencia identitaria de la posmodernidad", según ha advertido Jameson ${ }^{10}$ - ha contribuido (como lo han hecho, desde el punto de vista económico, los tratados bilaterales, por ejemplo) a establecer mil y una fronteras entre los individuos, esto es, a destruir los ya escasos factores de cohesión de comunidades como la latinoamericana. Consiguientemente, se han debilitado las condiciones para la emergencia de movimientos sociales que tengan posibilidades ciertas de desestabilizar las rígidas relaciones de poder instauradas. En verdad, la segmentación social de la que somos testigos y que se basa frecuentemente en el 'derecho a ser diferentes', en la práctica, consigue dividir de manera eficaz a individuos y comunidades, cuyas problemáticas históricas siguen siendo, sin embargo, absolutamente compartidas. De ahí que mantiene su interés y necesidad penetrar en y problematizar la, hasta cierto punto, gastada categoría de identidad latinoamericana, en la medida en que tal esfuerzo, por una parte, nos permita llevar a cabo una crítica al multiculturalismo anodino del que hemos dado cuenta, poniendo énfasis en las contradicciones que nos son comunes y que tal postura encubre; $y$, por otra, dé paso a una propuesta de vinculación comunitaria que, sin diluir las diferencias culturales, se oponga a la peligrosa fragmentación social, tan conveniente a los intereses de los poderosos. Todo ello en un contexto donde, insistimos, la concepción de identidad como esencia ya no responde a una realidad social, como tampoco a las mutaciones sufridas por las disciplinas sociales ni a sus más recientes debates.

mente dados, que así como expresa el grado de dominio alcanzado por la sociedad en su conjunto sobre la naturaleza bajo determinadas formas de organización social, sirve de marco general de referencias para la percepción que tienen los hombres de su lugar y su papel en la sociedad en que les ha tocado vivir" (29).

${ }^{9}$ Véase Cornejo Polar (1982 y 1996).

${ }^{10}$ Citado por Moraña (2000: 227). 
Es, pues, con esta panorámica en mente, que proponemos, en principio, leer la categoría de identidad latinoamericana como un conjunto de signos y relaciones que permitan construir vínculos de todo tipo entre los países, las culturas, las literaturas de nuestra región; como una noción que no pase por alto la diversidad, pero que permita enfatizar las semejanzas culturales y sociales, y que no escamotee las relaciones desequilibradas intra y extrarregionales. De esa forma, creemos, es posible subrayar las desigualdades sociales que caracterizan al continente, sin enmascararlas en simples diferencias culturales. En suma, nuestra apuesta a las diversas aproximaciones de la problemática de la identidad latinoamericana y sus aplicaciones en los estudios literarios y culturales consiste en intentar imaginarla como una compleja red de solidaridades (reales o virtuales) que permita reconocernos en diversos relatos que nos hermanan y nos diferencian de otras realidades. Las condiciones actuales demandan, además, la puesta en marcha de proyectos socioculturales alternativos a la denominada globalización. En ese sentido es que los esfuerzos por una integración a todo nivel, por hacer del continente una zona cultural y económica, debieran retomarse, repensarse con más bríos que antes, con mayor lucidez y determinación. Desde esa perspectiva también, nuestro perfil identitario continúa construyéndose.

\section{EL ESTUDIO DE LA IDENTIDAD LATINOAMERICANA EN LAS LETRAS: LITERATURA Y SOCIEDAD}

Uno de los vehículos privilegiados para la manifestación y, por ende, para el estudio de las identidades culturales lo constituye, sin lugar a dudas, la literatura, pues ésta "construye imágenes de la cultura que al reproducirla la interpretan, y al interpretarla la cambian, la cuestionan, la inventan" (Ostria, 1994: 82). Estudiar, pues, la identidad latinoamericana es de suyo vincular Literatura, Cultura y Sociedad.

La labor implica tender puentes entre la imaginación literaria y los procesos sociales, culturales e históricos; procesos de los cuales la Literatura como institución y como práctica concreta no constituye tan sólo una parte, sino que es a la vez origen y resultado, puesto que se conforma y reproduce histórica y socialmente.

Desde luego, en su carácter de expresión artística, la literatura no será mero reflejo de tales procesos, ni mecánica copia:

La sociedad propone, condiciona, presenta un repertorio (monumentos, formas, acontecimientos, tradiciones...): el creador dispone, juega, 
figura estos datos según sus fantasmas, sus intenciones estéticas, sus posibilidades individuales.[...] Su ojo, su psique, su brazo "mediatizan" y metamorfosean el patrimonio común, la materialidad objetiva (Brunel y Chevrel, 1994: 71-72).

No cabe, entonces, ni reducir los textos literarios a documentos históricos mediante un análisis sociológico, como tampoco realizar un análisis inmanentista que deje de lado el entorno. Uno de los propósitos de los estudios literario-culturales está en sacar a la luz el carácter histórico-social de los textos en pro de un cuestionamiento de las relaciones sociales existentes, considerando que "literatura e historia no se constituyen una a otra de manera externa, sino que se hallan indisolublemente ligadas por una relación de intrincación y articulación que constituye la condición de existencia histórica de algo como la literatura" (Balivar y Macherey, 1974: 23) ${ }^{11}$.

Por otra parte, no podemos perder de vista que la literatura no agota el sentido en sus condiciones históricas de producción, y que, si bien las propiedades del texto tienen que ver con las condiciones de enunciación, no se reducen a ellas. Texto y contexto, forma y contenido no podrán pensarse, desde este enfoque, en términos de exterioridad ni de separación, sino, muy por el contrario, como profundamente implicados y articulados, como una relación entre el texto y el mundo.

Un método de estudio que representa fielmente estas premisas, pues concibe al texto literario como un órgano profusamente tramado con la 'realidad', y que, además, surge de las demandas del mundo latinoamericano, es el analítico-explicativo-referencial, desarrollado por Antonio Cornejo Polar. Según lo caracteriza Raúl Bueno (2004), lo analítico en dicho modelo crítico se refiere, sumariamente, al estudio de la estructura textual; lo referencial, a la situación histórico-social, que no constituye aquí una entidad pasiva, sino parte activa y sustancial del proceso de producción textual; y, por último, lo explicativo, a la relación significativa y funcional entre texto y contexto de realidad. En este sentido, para Cornejo "leer los textos no es agotar los mensajes lingüísticos, sino hacer visibles los sentidos que producen dichos textos en sus profundas relaciones con la historia y la cultura que les concierne" (90).

Antonio Cándido (2007), para seguir con los investigadores latinoamericanos, también entiende esta interconfiguración obra-sociedad como la crítica más productiva. Desde su horizonte, habrá que determinar a tra-

\footnotetext{
${ }^{11}$ Citado por Perus (1995: 44).
} 
vés del análisis literario "si el factor social provee sólo materia (ambiente, costumbres, rasgos grupales, ideas) que sirve de vehículo para conducir la corriente creadora; o si, además de eso, es un elemento que actúa en lo que hay de más esencial en la obra de arte" (27).

Se trata, en resumidas cuentas, de asumir un abordaje dialéctico de la literatura y la sociedad que ojalá facilite la comprensión de ambas esferas que, como sugiere Roberto Schwarz (1989), ofrezca la posibilidad de construir un conocimiento nuevo capaz de explicar tanto la obra como la sociedad que la engendra.

Resta ahora terminar de dar el vistazo histórico a la categoría de "identidad”, desde el punto de vista de las disciplinas o ámbitos de reflexión por los que ella ha transitado, con miras a aproximarnos a una comprensión que funcionalice esta herramienta de análisis crítico.

Brevemente, el concepto de identidad hace su entrada en las ciencias sociales a través del psicoanálisis, cuya importante influencia en este campo como también en las humanidades provoca su traslado -junto con la de otras nociones como las de 'inconsciente', 'fluido de conciencia' o 'asociación libre de ideas' ${ }^{12}-$ a la literatura primero y, posteriormente, a la sociología, donde "no comienza a ocupar un lugar central sino a partir de la década de 1960" (Altamirano, 2002: 129) ${ }^{13}$. En el ámbito literario, entonces, la identidad se asocia a la conciencia del sujeto-personaje y suscita un análisis psicoanalítico de la obra.

En Latinoamérica, el término se emplea, aun después de la propagación del uso del vocablo "identidad" y hasta muy recientemente, en cuanto equivalente de un 'ser' y, en esa dirección, como una noción filosófica, metafísica, ontológica. Es aprehendida, por lo tanto, como una esencia estática, como un origen que hay que descubrir. De ahí que los pensadores se refieran a la identidad como sinónimo de especificidad, autenticidad, peculiaridad, etc.

Con el tiempo, el concepto se va dinamizando, pero también complejizando, en la medida en que pasa de ser una categoría ontológica a una social; o bien de concebirse como una esencia, a entenderse como una construcción derivada de la interacción social. Este último enfoque que, hasta el momento, parece haber prevalecido, reúne y reelabora planteamientos de otras áreas y disciplinas como la filosofía y la antropología, muchos de los

\footnotetext{
${ }^{12}$ Para la relación entre teoría psicoanalítica y literatura, véase Viñas Piquer (2002), pp. 541-554.

${ }^{13}$ Una entrada a la voz "identidad" que ofrece un panorama aún más detallado de su evolución, se encuentra en Carlos Altamirano (dir.) (2002), pp. 129-134.
} 
cuales han contribuido al desarrollo de la temática identitaria en algunos de los más recientes estudios literarios y culturales. He aquí algunos de ellos:

1. En primer lugar, la identidad debe concebirse como un devenir, como un proceso abierto, dinámico, de carácter orgánico, vivo. De modo que ésta podrá "aparecer como una adscripción 'fluida' que se genera en la interacción social, y no como una sustancia estable" (Altamirano, 2002: 131).

2. Las identidades colectivas [entre las que puede inscribirse la latinoamericana] pueden verse como "entidades relacionales constituidas por individuos vinculados entre sí a partir de un común sentimiento de pertenencia; lo cual implica compartir un núcleo de símbolos y representaciones sociales y, por lo mismo, una orientación común a la acción" (Giménez, 2000: 60). Estas identidades colectivas "no pueden considerarse como un sistema de suma cero donde las diferencias individuales se anulan para confluir en un interés colectivo común" (Valenzuela, 2000: 23).

3. La construcción de identidad corresponde a un proceso intersubjetivo de reconocimiento mutuo. En tal proceso se construye la conciencia del "nosotros" y, conjuntamente, la identificación de "los otros" (Valenzuela, 2000). Por consiguiente, las identidades "no sólo aparecen en relación al sí mismo sino también y muy especialmente en relación a los otros. [En efecto,] toda noción de identidad se completa con la imagen que una colectividad elabora sobre el resto del mundo y de la representación que esa cultura se hace de otras identidades, pero también con las imágenes que los demás proyectan sobre uno mismo" (Aínsa, 1986: 40).

4. Puesto que una identidad emerge y se afirma, adquiere su carácter distintivo y específico, "sólo en la confrontación con otras identidades en el proceso de interacción social" (Giménez, 2000: 50), frecuentemente su proceso de conformación implica una "relación desigual y, por ende, luchas y contradicciones" (50).

Destaquemos hasta aquí la vital importancia que el factor alteridad adquiere en la construcción y/o en la lectura de las diversas manifestaciones identitarias, sobre todo de una identidad como la latinoamericana, pues la compleja relación con 'lo otro', aquella presencia conflictiva y problemática, configura notablemente sus manifestaciones contextuales ${ }^{14}$.

Ahora bien, la perspectiva social-interaccionista tiende a enfatizar el ca-

${ }^{14}$ Véase, por ejemplo, nuestra interpretación de los cuentos de Julio Cortázar a partir de esa otredad radical, en Ostria (2009). 
rácter de adscripción de la identidad, su condición de proyecto, por sobre los factores históricos, las huellas de lo acontecido, que indiscutiblemente determinan también la identidad como devenir. Si la identidad es un "proceso histórico en permanente construcción y reconstrucción" (Valenzuela, 2000: 25), debe existir un pasado a partir del cual éste se construya y se reconstruya. Si es además "huella y sendero, marca y proyecto" (25), habrá, pues, una historia que sirva de sustento y cuyos rastros se expresarán, haya o no una voluntad explícita de hacerlo. Desde esa óptica, la identidad no será simplemente una adscripción fluida determinada por la contingencia, sino también, y primordialmente, un signo de la historia.

Puesto que la identidad cultural es, en definitiva una categoría sociocultural y no propiamente una literaria, queda preguntarse, por último, ¿cómo aprehender, en concreto, ese proceso histórico, ese devenir que constituye la identidad cultural, del texto literario? Desde luego, a través del lenguaje, del tratamiento artístico de la oralidad, del discurso, pero también a través de la relación que el propio texto establece con el mundo. Relación que puede revelarse en los múltiples planos de la obra, en las claves o principios medulares de las configuraciones narrativas, poéticas, en la construcción de subjetividades, de visiones y propuestas de mundo, en suma, en los constructos discursivos y semióticos que, en definitiva, actualizan, expresan de manera artística los conflictos asociados a la histórica alteridad que define nuestra América. La lectura será, asimismo, parte del proceso en el que esta identidad se manifieste. Un lector creativo, crítico, cómplice, en fin, activo, suscitará múltiples interpretaciones a partir de los procesos socioculturales inscritos en dichos constructos.

Para recapitular, postulamos, primero, acentuar la tensión histórica y dialéctica entre pasado y futuro, entre rastro y proyecciones de la noción de identidad colectiva proveniente de la sociología. Y, en seguida, insistir en la conflictiva alteridad como componente activo de la categoría; otredad que sigue determinando la tónica de un devenir identitario traumático y complicado. En consecuencia, nos aventuramos a pensar la identidad cultural latinoamericana como un entre las secuelas y los proyectos, la memoria y los sueños, un entre el discurso ajeno y el propio, y un entre el texto y la lectura.

III

Volver a estudiar la identidad latinoamericana tendrá sentido si nuestras investigaciones consiguen revitalizar en cierta medida las lecturas críticas en las que se empalman literatura y sociedad, con miras a revalorizar las 
esferas históricas e ideológicas en los estudios literarios y culturales. La categoría representará un aporte, asimismo, si logramos inyectarle una auténtica carga crítica, a través del énfasis en el conflicto -y no en la síntesis armoniosa- de los procesos culturales, sociales e históricos que van configurando lo latinoamericano. Finalmente, la tarea valdrá la pena en la medida en que seamos capaces de conectar la temática a las circunstancias históricas y políticas actuales, en las que el evidente desequilibrio de poderes, la consiguiente acentuación abismal de las contradicciones, la falta de responsabilidad política y ética en las sociedades civiles, claman por la creación de nuevas formas de vinculación social (ancladas principalmente en las problemáticas históricas comunes), capaces de traspasar fronteras nacionales, partidistas, culturalistas; formas que abran paso a la posibilidad, al menos, de cambios y acciones sociales.

\section{REFERENCIAS}

Aínsa, Fernando (1986). Identidad cultural de Iberoamérica en su narrativa. Madrid, España: Gredos.

Altamirano, Carlos (Dir.) (2002). Términos críticos de la sociología de la cultura. Buenos Aires, Argentina: Paidós.

Balivar, Etienne y Machery, Pierre (1974). "Presentación al libro de Renée Balivar", Les Franchise fictifs. París, Francia: Hachette Littérature.

Brunel, Pierre y Chevrel, Yves (Dirs.) (1994). Compendio de literatura comparada. México: Siglo XXI.

Bueno, Raúl (2004). Antonio Cornejo Polar y los avatares de la cultura latinoamericana. Lima, Perú: Fondo Editorial Universidad Nacional Mayor de San Marcos.

Campra, Rosalba (1998). América Latina: La identidad y la máscara. México: Siglo XXI.

Cándido, Antonio (2007). Literatura y sociedad: estudios de teoría e historia literaria. Traducción Jorge Ruedas de la Serna. México: UNAM-CCYDEL. (Primera edición: 1965. Literatura e sociedade: estudos de teoria e história literaria. Sao Paulo, Brasil: Companhia Editora Nacional).

Cornejo-Polar, Antonio (1982). "El problema nacional en la literatura peruana”. Sobre literatura y crítica latinoamericanas. Caracas, Venezuela: UCV.

------ (1996). "Una heterogeneidad no dialéctica: sujeto y discurso migrantes en el Perú moderno". Revista Iberoamericana LXII / 176-177, 837-844.

Dorra, Raúl (1986). "Identidad y literatura. Notas para un examen crítico". En Saúl Yurkievich (Ed.), Identidad cultural de Iberoamérica en su literatura. Madrid, España: Alambra.

García Canclini, Néstor (1990). Culturas híbridas. Estrategias para salir y entrar de la modernidad. México: Grijalbo. 
Giménez, Gilberto (2000). "Materiales para una teoría de las identidades sociales”. En José Manuel Valenzuela Arce (Coord.), Decadencia y auge de las identidades. Cultura nacional, identidad cultural y modernización. México: El Colegio de la Frontera Norte; Plaza y Valdés Editores.

Habermas, Jürgen (1998). Identidades nacionales y postradicionales. Madrid: España, Tecnos.

Hall, Stuart (1991). "Old and New Identities, Old and New Ethnicities". En Anthony King (Ed.), Culture, Globalization and the World-System. Contemporary Conditions for the Representations Identity. Binghamton, Estados Unidos: Dept. of Art and Art History, SUNY-Binghamton.

Henríquez Ureña, Pedro (1972). “Tradición y rebelión” (fragmento de "El descontento y la promesa”). En Alberto M. Vásquez (Ed.), El ensayo en Hispanoamérica. New Orleáns-México: Ediciones El Colibrí.

Martín Barbero, Jesús (1987). De los medios a las mediaciones. México: Gustavo Gili.

----- (2000). “Globalización y multiculturalidad: notas para una agenda de investigación”. En Mabel Moraña (Ed.), Nuevas perspectivas desde / sobre América Latina: El desafío de los estudios culturales. Santiago de Chile: Cuarto Propio.

Moraña, Mabel (2000). "De metáforas y metonimias: Antonio Cornejo Polar en la encrucijada del latinoamericanismo internacional”. En Mabel Moraña (Ed.) Nuevas perspectivas desde/sobre América Latina: El desafío de los estudios culturales. Santiago de Chile: Cuarto Propio.

Ortiz, Renato (1996). Mundialización y cultura. Buenos Aires, Argentina: Alianza.

------ (2000). "Diversidad cultural y cosmopolitismo". En Mabel Moraña (Ed.), Nuevas perspectivas desde/sobre América Latina: El desafío de los estudios culturales. Santiago de Chile: Cuarto Propio.

Ostria, Mauricio (1994). "Marginalidad y diferencia: La situación de la literatura y la cultura latinoamericanas", Reflexiones sobre el V Centenario. Rosario, Argentina: Universidad Nacional de Rosario Editora.

Ostria, Olga (2009). "El sentimiento de no estar del todo: el discurso identitario latinoamericano en dos cuentos de Julio Cortázar”. Revista Chilena de Literatura 75, noviembre, 295-306.

Perus, Francoise (1995). El realismo social en perspectiva. México: Instituto de Investigaciones Sociales, UNAM.

Schwarz, Roberto (1989). Que horas sao? San Pablo, Brasil: Cía. das Letras.

Valenzuela Arce, José (2000). "Introducción" e "Identidades culturales. Comunidades imaginarias y contingentes”. En José Manuel Valenzuela Arce (Coord.), Decadencia y auge de las identidades. Cultura nacional, identidad cultural y modernización. México: El Colegio de la Frontera Norte; Plaza y Valdés Editores.

Viñas Piquer, David (2002). Historia de la crítica literaria. Barcelona, España: Ariel. 